\title{
O Cáucaso, distante e próximo
}

\author{
Boris Schnaiderman
}

"Não me cantes canções da Geórgia distante" ê o início de um famoso poema de Púchkin. Mas as terras do Cáucaso, de fato tão distantes dos grandes centros da Rússia, foram se tornando, através do tempo, cada vez mais próximas culturalmente. É preciso ter isto em mente para se avaliar em toda a extensão o que representam para os russos os acontecimentos que ali se desenrolam nos últimos tempos.

Tratava-se de terras distantes, sim, mas que sempre exerceram um fascínio peculiar, situadas que estavam na zona limítrofe entre o império russo em expansão e o Oriente Médio. No início do século XIX, era bem recente ali a instalação do domínio russo, mas já então o Cáucaso se constituíra num pólo de atração. Basta pensar, neste sentido, no que ele representou para algumas das principais figuras da vida cultural russa.

Púchkin esteve lá mais de uma vez e tem muitos poemas inspirados por temas caucasianos. "O prisioneiro do Cáucaso" é sem dúvida um dos grandes momentos do romantismo russo; tudo nesse poema narrativo é bem romântico: o tema, o léxico, a exaltação dos montanheses e da "vida primitiva". Se Púchkin teve em relação ao romantismo uma atitude bem crítica, chegando freqüentemente ao questionamento frontal, este poema expressou um momento de plena identificação. $O$ deslumbramento com as montanhas nevadas e com aqueles povos tão diferentes parece que predispunha à idealização, ao devaneio, e fazia adormecer o espírito crítico.

A própria biografia do poeta ficou muito ligada ao Cáucaso. Assim, num período em que era suspeito politicamente e estava sob vigilância, pediu sua incorporação ao exército, a fim de participar da Guerra Russo-Turca de 1828-29. Isso lhe foi negado, mas assim mesmo viajou para o Cáucaso, para se incorporar às tropas que estavam avançando pela atual Armênia turca. Vários testemunhos mostram que teve então um comportamento temerário, quase suicida. Finda a guerra, reelaborou o diário de campanha, que resultou num dos seus escritos em prosa mais importantes: Viagem a Arzrum.

Mais crucial ainda aparece o Cáucaso na vida e na obra de outro grande poeta russo da época, M. I. Lérmontov. Oficial do exército, ele foi preso em 1837 por ter escrito um poema indignado após a morte de Púchkin em duelo, onde ele o mostrava acossado pela sociedade de seu tempo, pelas pessoas chegadas à corte do czar. Depois de solto, foi transferido para o Cáucaso, para um regimento em luta contra montanheses revoltados. $\mathrm{Na}$ Geórgia, estudou línguas caucasianas e interessou-se vivamente pelas tradições populares. Um exemplo disso é o seu conto “Achik Kerib”, na realidade anotação de uma lenda caucasiana, muito presente sobretudo no Azerbeidjã (Lérmontov a define como um "conto turco"), que inspirou o filme $O$ trovador Kerib, dirigido por S. Paradjanov e exibido recentemente em São Paulo.

Se em sua obra o romantismo é acompanhado de uma visão crítica muito aguda sobre a sociedade de seu tempo, o Cáucaso surge como lugar de beleza e sonho, como que o oposto das misérias que via. Isto aparece também no seu grande romance Um herói do nosso tempo ${ }^{(1)}$.
BORIS SCHNAIDERMAN é professor aposentado do curso de russo do Departamento de Línguas Orientais da FFLCH da USP, tradutor e ensalsta. É autor de Turbilhão e sementes (Editora Duas Cidades) e Dostoiévski - poesia e prosa (Editora Perspectiva).
1 Ele foi traduzido para o portugués por Paulo Bezerra (Rio de Janeiro, Editora Guanabara, 1988).

\section{Setembro \\ Outubro \\ Novembro}




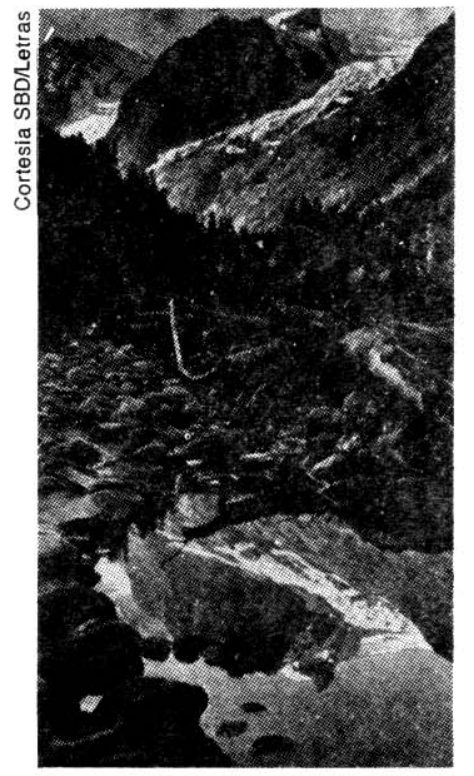

$\begin{array}{lllllll}R & E & V & \text { I } & S & T & A\end{array}$
Depois de uma estada em Petersburgo e tendo servido nas proximidades, foi enviado novamente para o Cáucaso. Pressentia então claramente o fim que o esperava (poucos meses antes, escrevera um poema em que se via "com chumbo no peito, jazendo imovel, ao calor do meio-dia, num vale do Daguestão") e exclamou em verso: "Adeus, Rússia não lavada, / País de escravos, país de senhores". A caminho do regimento em campanha, recebeu autorização para um tratamento com águas minerais em Piatigorsk. $\mathrm{E}$ ali foi provocado para um duelo, visto geralmente pelos biógrafos como um verdadeiro assassínio, que teve lugar perto da cidade, na encosta do monte Machuk, aquele Machuk que "se eleva como um felpudo gorro persa", conforme escrevera no romance. Tinha então 27 anos incompletos.

A. S. Griboiedov foi outra personalidade russa muito rica ligada ao Cáucaso e ao Oriente Médio em geral. Ele é conhecido principalmente pela sua peça $A$ desgraça de ter esptrito, embora tenha escrito várias outras, que não se comparam em importância à sua obra máxima.

Depois de ter servido no exército, inclusive participando da guerra com $\mathrm{Na}$ poleão, entrou para o serviço diplomático, sendo nomeado em 1818 secretário da embaixada russa na Persia. Isso implicava em freqüentes estadas na Geórgia, pois sua capital, Tíflis (hoje Tbilíssi, a forma georgiana desse nome), era uma verdadeira ponta de lança russa dirigida para o Oriente Médio. Em 1822, tornouse funcionário diplomático adido ao governador-geral da Geórgia. Em 1825, A desgraça de ter esptrito foi proibida pela censura, passando a circular copiosamente em cópias manuscritas. Foi preso na Geórgia em 1826, como implicado na revolta dos "dezembristas", que tinha ocorrido em Petersburgo, para onde seria levado. Depois de seis meses, e tendo escrito ao czar, protestando inocência, foi libertado e reintegrado na carreira diplomática. Regressando ao Cáucaso, encontrou a região em polvorosa, devido ao início da Guerra Russo-Persa. No ano seguinte, ficou encarregado das relações com a Pérsia e a Turquia, ambas então em guerra com a Rússia.

Acompanhou as tropas russas, que avançavam pela Armênia em perseguição aos persas, e levou a efeito as negociações de paz. Depois de assinado o respectivo tratado em 1828, foi nomeado ministro-plenipotenciário em Teerã. Numa nova estada em Tíflis, casou-se com uma georgiana, filha do poeta romântico A. G. Tchvtchadze. Em 30 de janeiro de 1829, uma turba enfurecida destruiu a embaixada russa em Teerã e matou Griboiedov.

Personalidade enigmática e contraditória, ele atraiu a atenção de alguns dos maiores escritores russos. Púchkin relata, em Viagem a Arzrum, que estando a caminho do exército em operações, ao atravessar a fronteira entre a Geórgia e a Armênia, encontrou um carro de bois, acompanhado de alguns armênios, que vinham de Teerã, levando para Tíflis o corpo de Griboiedov.

"Eu não esperava encontrar algum dia o nosso Griboiedov! Separara-me dele no ano 


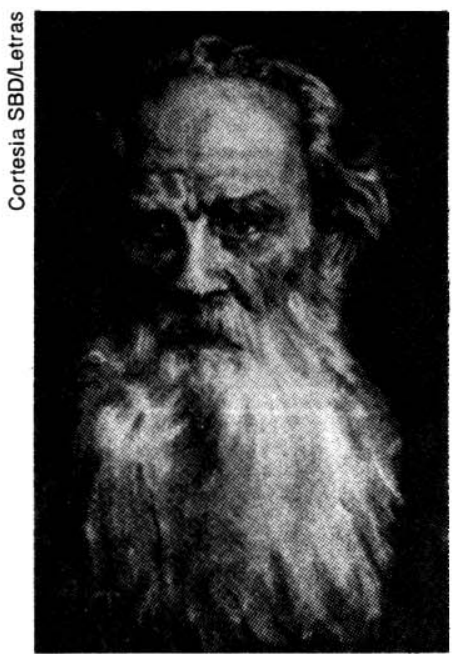

Leon Tolstói (1828-1910)

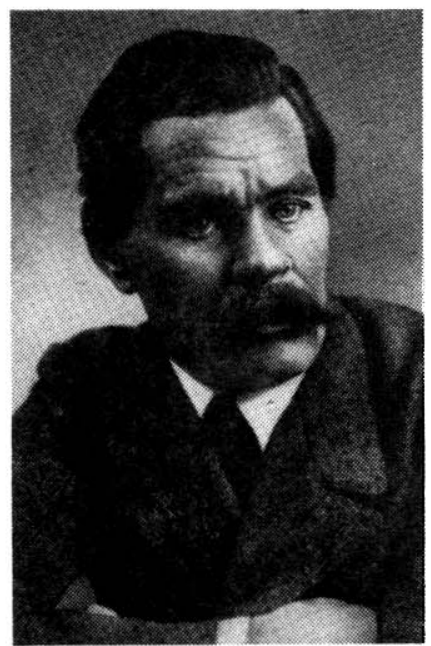

Máximo Górki (1869-1936) forme já mostrei de modo mais desenvolvido e com estudo textual, em meu pequeno livro sobre Tolstoi ${ }^{(2)}$.

O Cáucaso aparece ainda, soberano, na última grande obra de ficção que ele nos deixou: Khadji-Murat ${ }^{(3)}$. Fico sempre surpreendido com a relativamente pouca importância que se atribui no Ocidente a este livro de menos de 150 páginas, e que Tolstói não considerava concluído, embora tivesse trabalhado nele muitos anos. Aparece ali em toda a pujança o grande criador de vidas que foi o autor de Guerra e paz e Ana Karênina, mas também o novelista de A morte de Ivã Ilitch e Padre Sérgio. Surgem os vastos panoramas, porém trabalhados de modo mais condensado, mais fechados nos limites de uma esfera, como diria Cortázar ${ }^{(4)}$. E o resultado é certamente uma obra-prima, que não considero inferior, embora em outro plano, a estas duas novelas.

No meio das montanhas do Cáucaso, de um lado estão os russos, com a sua máquina de guerra, os soldados trazidos dos quatro cantos do imperio, a sua burocracia sonolenta, a distância estabelecida em relação aos povos dominados, a máquina que se liga por mil fios inviś́veis com o grande comando em Petersburgo e com o próprio czar Nicolau I, brutal e auto-suficiente, o verdadeiro “gendarme da Europa". E do outro lado, estão os montanheses que lutam pela independência, sob o comando do líder religioso e guerreiro Chamil. Mas, guerreando por uma causa justa, eles não são por isso menos cruéis e prepotentes, menos absorvidos em lutas de poder, menos dispostos a enganar e oprimir o próximo. E entre os dois, Khadji-Murát, o guerreiro montanhês, que se passa do lado de Chamil para os russos, e depois tenta fugir dos russos para voltar às montanhas, mas ê morto com o grupo de seus fiéis seguidores.

Assim, Tolstói certamente ajusta contas com suas próprias ilusōes da mocidade. Como estamos longe dos deslumbramentos de Os cossacos! A primeira vez que li KhadjiMurát, na adolescência, identifiquei-me totalmente com a luta de Chamil e, embora fascinado pelo texto, fiquei bastante mal impressionado com o desmascaramento das debilidades de ambos os lados. Mas, passados os anos, só podemos admirar cada vez mais a lucidez com que Tolstói viu os extremos de fanatismo e violência a que podia levar aquele movimento religioso. Parece que ele estava prevendo certas manifestações do fundamentalismo em nossos dias. Pode-se não concordar com a doutrina da não-resistência ao mal pela força (como sustentá-la depois dos horrores do hitlerismo?), mas não há como deixar de reconhecer a clarividência de muitas das abordagens de Tolstói.

Máximo Górki foi outro dos grandes escritores russos muito ligado àquelas terras. Ele residiu alguns anos em Tiflis, e a Geórgia aparece em muitas de suas histórias. "Meu companheiro de estrada" é uma narrativa sobre uma daquelas caminhadas de milhares de quilometros que empreendeu, desta vez de Odessa a Tiflis, em companhia de um príncipe georgiano de dezenove anos, completamente desarvorado (seria mesmo príncipe?) e que é descrito como "um rapaz ingênuo, selvagem, sem qualquer preparo, alegre quando saciado, melancólico ao sentir fome, um animal vigoroso e bonachão". Pois bem, aquele "animal vigoroso", que o futuro escritor alimentara e protegera na caminhada, abandonou-o sozinho depois que chegaram. Há nesse conto um encanto peculiar na chegada a Tiflis, na descrição da cidade que escurecia. E o mesmo encantamento aparece nas seqüências de "Sobre o primeiro amor" em que ele narra os meses que passou ali com a primeira companheira. E também nas páginas finais de "Uma mulher", onde a cidade surge ainda mais encantada, vista entre as ameias do castelo que servia de prisão e onde Górki estava encerrado( ${ }^{(5)}$

Realmente, foi muito grande a presença dos temas caucasianos na cultura russa das décadas de 1910 e 1920 . A paixão de Vielimir Khlébnikov pelo Oriente não poderia deixar de levar ao Cáucaso aquele incansável andarilho, e ele escreveu muitos poemas marcados pelo contato com a região. Num deles evoca Lérmontov e seu "verso de ferro, inundado de amargura e raiva" e seu fim "na pátria da morte bela". Em outro, lembra um "riacho de água fria" junto ao qual se deteve quando a Tcheká, a polícia política dos primeiros tempos da Revolução, o convocou para interrogatório a uns quarenta quilômetros de distância. São poemas de uma beleza estranha, que se aproximam muito mais que outros em sua obra daquilo que nós costumamos chamar de "verso livre".

Maiakóvski era de famńlia russa, mas nasceu em Bagdádi, um povoado da Geórgia que tem o seu nome. Sua infância ali foi evocada por ele mais de uma vez, inclusive na 
surpreendente autobiografia "Eu mesmo"(6). Surpreendente pelo espírito desabusado, pela concisão e violência com que os fatos são apresentados, sem nenhuma autocomiseração e nenhuma "evocação comovida". Em Sobre isto, há uma passagem em que ele se imagina assassinado como Lérmontov, atacado pelos medíocres e intrigantes, e tem-se então, certamente, um dos momentos mais dramáticos do poema ${ }^{(7)}$.

Nos anos de guerra civil e fome, muitos artistas e escritores procuraram fugir à vida difícil nos grandes centros e alguns acabaram estabelecendo-se no Cáucaso. Foi na Geórgia que se desenvolveu, na época, boa parte da obra de A. Krutchônikh, tão importante para a linguagem poética de vanguarda que ele passou muitos anos, a partir de 1930, completamente esquecido e sem conseguir publicar uma linha sequer, a não ser trabalhos sobre bibliografia. Em alguns poemas seus a maneira arrevesada que os caucasianos têm de pronunciar o russo foi utilizada não como arremedo e caçoada apenas, mas como um meio expressivo que tinha sua riqueza e graça.

Krutchônikh pertenceu a um grupo de vanguarda de que participaram, ainda, o pintor Michel Ledentu, que, apesar do nome, não era francês, e Iliá Zdanévitch, poeta e pintor que se consagraria como Iliazd.

Tendo sido, ao lado de Krutchônikh, um dos primeiros cultores da zaúm, ou linguagem transmental, Iliazd transferiu-se para Paris em 1921. A partir desse ano, viveu sempre no Ocidente, participando das experiências artísticas mais arrojadas, convivendo com Picasso (com quem colaborou em nove livros), Chagall, Max Ernst, Paul Eluard, etc. Trouxe uma grande contribuição à tipografia artística e ocupou-se em Paris da edição de obras importantes caídas no esquecimento. É também autor de romances e estudos, muitos deles sobre cultura georgiana.

O mesmo grupo de vanguarda a que pertenceram Krutchônikh e Iliazd descobriu e divulgou a obra do grande pintor "primitivo" georgiano Niko Pirosmanichvíli.

O poeta Óssip Mandelstam foi outro apaixonado pelo Cáucaso dos anos de guerra civil. A região está muito presente em sua obra e a ela dedicou vários escritos em prosa, entre os quais se destaca "Viagem à Armênia", onde há descrições impressionantes sobre a vida numa ilha do lago Sevan.

O Cáucaso ocupa também um lugar importante na vida e na obra de Boris Pasternak. Segundo conta em seu Ensaio autobiográfico, isto aconteceu na década de 1930. Ele foi visitado pelo poeta georgiano Paolo Iachvfli, que depois lhe ofereceu abrigo em Tíflis, quando Pasternak, separado de sua famf́lia, não tinha para onde ir com a companheira, que se tornaria sua segunda mulher. Em casa de Iachvíli conheceu então alguns dos principais representantes da poesia georgiana da época, que ele traduziria para o russo. Entre eles ligou-se particularmente com outro importante poeta, Tizian Tabidze. No período da repressão stalinista, Iachvíli e Tabidze foram acusados de conspiração e presos. O primeiro suicidou-se na prisão, o segundo foi fuzilado. "O destino de ambos, ao lado do destino de Tzvietáieva, haveria de se tornar o meu maior desgosto", escreveu Pasternak no mesmo Ensaio autobiográfico.

Mas sua atração pelo Cáucaso é bem anterior a este mergulho na realidade georgiana daqueles dias. Assim, no poema "Sobre estes versos", que é de 1917, lemos: "Darial me serve de abrigo -/ De inferno, arsenal, paiol. / E embebo a vida no vinho./ Lábios. Tremor. Lérmontov" ${ }^{\prime(8)}$. (Darial é o desfiladeiro que constitui verdadeira entrada para a região.) Como se vê, por mais que os acontecimentos trágicos desabem sobre o Cáucaso, nada consegue abafar no universo simbólico dos russos aquele disparo desferido contra Lérmontov.

Mas não foi só graças à literatura que ele ficou marcado pelo Cáucaso. Por exemplo, o simples nome de Armênia evoca um país de colorido forte, exuberante, graças não só à paisagem, mas também, e sobretudo, à sua pintura. Se o nome de Martiros Sarian é mundialmente conhecido e reproduções de quadros seus podem ser encontradas no Ocidente, de modo geral se conhece pouco a pujança das artes plásticas daquele paŕs. Jerusa, minha mulher, chamou-me a atenção para o seguinte: por mais que os artistas armênios se tenham submetido às normas rígidas do realismo socialista, ao mesmo tempo conseguiam meios de subvertê-las, de fazer valer o seu senso pictórico, acima das exigências do momento. Assim, às vezes num simples cartaz, conforme pudemos observar em Erevan, um recurso gráfico mais arrojado rompia a monotonia quase obrigatória. $\mathrm{E}$

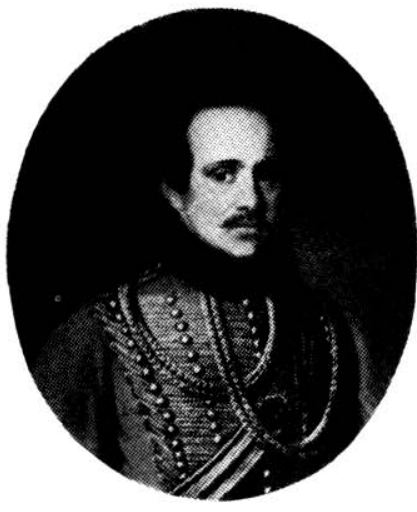

Mikhail Lérmontov (1814-1841)

2 Tolstoi - antiarte e rebeldia, Boris Schnaiderman. São Paulo, Editora Brasiliense, 1983.

3 Traduzi este livro e pude reelaborar duas vezes a minha traduçăo. Última versáo: Khadji-Murát, Leấo Tolstoi. Săo Paulo, Editora Cult-ix, 1987.

4 Ultimo round, Julio Cortázar. Cidade do México, Siglo Veintiuno, 1969. O mesmo texto foi incluído em Valise de cronopio, a coletânea brasileira de ensaios de Cortázar, editada pela Perspectiva.

5 Traduzi esses três contos. "Meu companheiro de estrada" e "Uma mulher" estão no livro Contos, Máximo Górki. Rio de Janeiro, Editora Philobiblion, 1985. "Sobre o primeiro amor" saiu na Antologia do conto russo (vol. VIII), publicada pela Editora Lux, do Rio de Janeiro, 1962.

6 Minha tiaduçáo desse texto figura em dois livros: A poética de Maiakovski através de sua prosa, Boris Schnaiderman. Săo Paulo, Editora Perspectiva, 1971 e Poemas de Maiakovski. Augusto e Haroldo de Campos e Boris Schnaiderman. Săo Paulo, Perspectiva, 1982.

7 Há uma traduçáo de Haroldo de Campos e minha no livro: Poesia russa moderna, Augusto e Haroldo de Campos e Boris Schnaiderman. São Paulo, Brasiliense, 1985. Outro fragmento do mesmo poema figura ali em tradução de Augusto de Campos.

8 Traduçăo de Haroldo de Campos no livro citado.

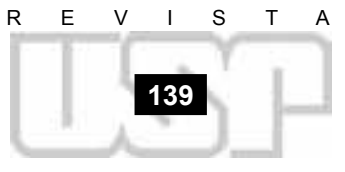


9 Indolevropeiskil iazik I indolevropéitzi (A lingua indo-européia e os indo-europeus), V. V. Ivanov $\theta$ T. Gamkrelidze. Ediçăo da Universidade de Tbillssi, 1984.

10 Uma informaçáo sobre esses traba. Ihos pode ser encontrada em: $O$ problema do Inconsciente, F. V. Bassin. Rio de Janeiro, Editora Civilizaçăo Brasileira, 1981. Traduzido do russo por Ana Loocádia Prestes.

11 Haveria, evidentemente, muito mais a dizer sobre isso, do ponto de vista da historia politica. aquilo parecia bem condizente com o país cuja tradição artística vem de tão longe, como atestam as suas famosas iluminuras medievais, as igrejas de bela arquitetura, desde os primeiros séculos do cristianismo, etc.

A música da região é muito apreciada pelos russos, bem como a ópera e o balé. É verdade que no Ocidente pensa-se logo em Aram Khatchaturian, mas para o ouvido russo o nome Cáucaso evoca tamberm outras ressonâncias.

E não esqueçamos que provavelmente o mais criativo dos cineastas soviéticos de hoje é o georgiano de origem armênia, Sierguei Paradjanov. Isso também não é um fato isolado. Cineastas do Cáucaso contribuíram fortemente para o florescimento do cinema soviético da década de 1920. Os estúdios de Tbilíssi, sobretudo, desempenharam então um papel muito importante. E esta presença de caucasianos no cinema soviético tem sido constante.

Em relação à história desses contatos entre o Cáucaso e a Rússia, é importante frisar o seguinte: se o primeiro impacto foi uma expressão do espírito romântico, com a atração pelo "primitivo", o "espontâneo", o “exótico", na realidade os russos, embora ocupantes e invasores, tinham muito a aprender com os povos dominados, alguns de civilização bem mais antiga, e que souberam criar grandes centros de cultura.

Alguns dos importantes poetas russos se dedicaram a traduzir obras poéticas desses povos. O simbolista $\mathrm{C}$. Balmont se aplicou ao grande poema georgiano, $\boldsymbol{O}$ cavaleiro da pele de tigre, de Chota Rustavéli (século XII), que também foi traduzido, já na década de 1960, por Nicolai Zabolotzki. O simbolista Valéri Briussov dedicou-se ao estudo da literatura armênia e traduziu muitos textos armênios para o russo. $O$ poeta contemporâneo Pável Antokólski traduziu a lenda tradicional Leili e Medjnun, na versão do poeta azerbeidjano do século XII, Nizami Gandjevi. Outros se aplicaram à versão também azerbeidjana de Fizuli (século XVI), poeta que teve um papel importante em toda a literatura do Oriente Médio.

Os estudos lingüísticos e semióticos da União Soviética devem muito a pesquisadores do Cáucaso. Era armênio o criador da "teoria estadial" na lingüística, N. I. Marr que, a partir do estudo das línguas caucásicas que ele denominava “jaféticas”, estabeleceu uma íntima relação que existiria sempre entre o desenvolvimento de uma língua e o estádio econômico e social da sociedade em que ela se desenvolve. Sua teorização teve numerosos adeptos e, a partir da década de 1930, a preocupação com os "estádios" foi central nos estudos de linguagem soviéticos, não obstante o falecimento de Marr em 1934. Mas em 1950 o predomínio dos marristas na lingüística soviética foi bruscamente cortado, com a publicação de dois trabalhos assinados pelo próprio Stálin, sobre questões de linguagem e sua relação com o marxismo, e onde se fazia uma crítica frontal à teoria dos "estádios".

Nos estudos lingüísticos dos últimos anos é muito marcante a presença de nomes caucasianos, entre os quais os dos armênios I. D. Apressian e S. E. Chaumian. O trabalho em colaboração com lingüistas do Cáucaso foi muito importante no desenvolvimento dos trabalhos de lingüística indo-européia de V. V. Ivanov, que elaborou com o georgiano T. Gamkrelidze um livro que teria presença muito forte nos estudos recentes sobre a origem do proto-indo-europeu(9).

Esta marca do Cáucaso na cultura russa abrange os campos mais diversos. Nos últimos anos, vêm tendo grande repercussão tanto na Rússia como no Ocidente os trabalhos sobre o inconsciente da escola de D. Uznadze, que foram se desenvolvendo a partir da década de 1950 junto à Universidade de Tbilíssi(10).

Enfim, é impossível abranger num artigo tudo o que há de importante sobre esse tema. E, além disso, ocorrem inevitáveis lapsos. Assim, até agora não li a ficção do georgiano N. V. Dumbadze, muito traduzido na Rússia e tão admirado pelo meu amigo Paulo Bezerra.

Nestes dias, em que se chegou a um momento crucial na relação entre os russos e o Cáucaso, vale a pena pensar um pouco no longo caminho do contato entre esses dois mundos, e sobretudo na grande contribuição que esses países convulsionados trouxeram à cultura, embora isso seja pouco lembrado no Ocidente ${ }^{(11)}$. 